jerks moderate and equal. Extensor plantar response right and left. Head retraction persisted.

Lumbar puncture was again performed, and the withdrawal of about $1 \mathrm{drachm}$ sufficed to reduce the pressure to normal.

September 30,1928 . Temperature had fallen to normal, pulse was 52. The patient was less drowsy; the oedema of the face had subsided, and the swelling of the socket was less.

October 1, 1928. General condition was improved. Temperature normal, pulse 52. The grips were equal in strength, and a bilateral flexor response was present. Intense chemosis still caused prolapse of conjunctiva between the lids.

From the last date there has been a gradual and steady improvement; on the 7th the conjunctiva was able to be replaced and the lids were strapped over it ; there is now-October 16, 1928-very little chemosis. On the 11 th the patient was allowed to get up and complained of no headache as a result; he now feels perfectly well.

The clinical picture was undoubtedly one of meningitis, and the condition must be considered to have been one of aseptic serous meningeal effusion. Comparable, in a sense, are the pleural effusion which may occur in conjunction with a liver abscess, and the ascites with intestinal new growth.

I am indebted to Miss I. C. Mann for permission to publish this case.

\title{
UNUSUAL CASE OF MACULAR DEGENERATION
}

BY

Frank W. LaW, M.A., M.B.

SENIOR HOUSE SURGEON, ROYAL LONDON OPHTHALMIC HOSPITAL

A.M., widow, aged 46 years, was admitted to this hospital on August 21 , 1928. She complained that, although vision had been good in both eyes without glasses up to six years ago, and with glasses until two years ago, since that time there had been a gradual deterioration in both eyes. No other symptoms were complained of except a very ill-defined and mild ache in the region of the right eye for the last year. She was wearing + 3.0 D.Sph. R. and L.

$$
+0.5 \text { D.Cyl. }-180^{\circ}
$$

On admission, the eyes were normal externally, the pupils active, and the tension normal. The right optic disc was normal; in the region of the macula there was vaguely defined a circle, of diameter about 1.5 times that of the disc; the circle could with difficulty be 
seen in its entirety, and had a pale greyish tinge in comparison with the normal retina. The upper part of the area thus demarcated was definitely depressed, the very fine vessels crossing the edge being seen to dip down into the area. The lower part was well defined in its periphery, being of a markedly lighter colour than the rest, and closely resembling in appearance a colourless or yellowish subhyaloid exudate. That this appearance was indeed due to the presence of a fluid occupying the lower segment was proved by causing the patient to lie for two hours on her right side, when the lighter area was found to have altered its position and to be then lying in the temporal segment. No other fundus abnormality was found.

At the left macula was found a small irregular dark grey area, presumably pigment, resembling the more usual types of pigmentary macular degeneration.

Vision on admission was: R.E. (with glasses) 6/60. L.E. (with glasses) $6 / 24$ (pt.). Both visual fields were full; the right blind spot was normal, the left could not be elicited. There was no central scotoma in either eye; on the Bjerrum screen, the $10 \mathrm{~mm}$. white fixation disc, when seen by the right eye, was described as of irregular shape, as large as a crown, with an irregular black centre, from which black "spokes" radiated to the periphery in all directions. The left eye saw it as a similarly irregular area, the size of a shilling or a little larger, the "spokes" being present but less marked.

Colour vision was normal. The urine was acid in reaction and contained no sugar nor albumen. The Wassermann test was positive.

Treatment consisted in atropine drops, hot box to the right eye twice a day, and hot air baths on alternate days; the internal administration of potassium iodide, and the daily inunction of $1 \mathrm{drachm}$ of oleate of mercury. In addition, 5 intravenous doses of N.A.B. have so far been given. Apical infection of the lower incisors was found to be present, and these teeth were extracted.

October 1,1928. There is no change observable in the condition on ophthalmoscopic examination. Vision is now : R.E. (with glass) $3 / 36$. L.E. (with glass) 6/24 (all). According to the patient (who is of a very neurotic disposition and whose answers in this respect are probably unreliable) there is considerable variation in visual acuity from day to day.

The condition would appear to be one of persistent decolourised subhyaloid haemorrhage in the region of the right macula, with pigmentary degeneration of the left macula.

$\mathrm{I}$ am indebted to $\mathrm{Mr}$. Maurice $\mathrm{H}$. Whiting, for his permission to report this case. 